\title{
Morphological markers with a triploid set of chromosomes by breeding of apple tree at the polyploid level
}

\author{
Sergey Makarenko ${ }^{1 *}$ \\ ${ }^{1}$ Ural federal agricultural research center of the Ural department of the RAS, 620142, Yekaterinburg, \\ Russia
}

\begin{abstract}
The results many years of research in the conditions of the Altai low mountains are given the assessment of hybrid apple populations from heterploid crosses according to the characteristics: resistance to scab, degree of culture, growth strength, stem thickness, leaf thickness, leaf index, morphometry of the graft and stipules, ploidy. The correlation was established by the studied indications with the triploid set of chromosomes of hybrids from heteroploidy's crosses. It is shown that the cytological assessment of karyotypes selected for a complex of morphological features is required in a significantly smaller volume, and varieties of siberian selection are capable for partial formation of germ sacs with a diploid set of chromosomes. Morphological markers for apple tree selection at the polyploid level were determined by identifying seedlings in the juvenile stage with a triploid set of chromosomes inside a hybrid population. The application of morphological markers makes it possible to identify from 14 to $100 \%$ of seedlings with a triploid set of chromosomes in dependence on the original tetraploid form.
\end{abstract}

\section{Introduction}

Polyploidy of many cultivated plants is the foundation of evolution [1].

Their advantage is manifested in a wide geographical spreading, in achievement greater genetic, species, ecotypic and biogenetic variability, better ecological adaptation, change the morphology, biochemistry and physiological characteristics of plants $[2,3]$.

At the beginning of the last century, according to the results of the evaluation of the karyotype of apple sorts were identified samples from varieties of polyploid nature with a content in the nuclei of somatic cells chromosomes of 1.5-2.0 times $(2 n=51-68)$ as much than in diploid $(2 \mathrm{n}=34)[4,5]$.

In the global apple tree assortment have been identified spontaneous triploids, of which 15 have commercial value $[3,15]$. The spontaneous nature of their origin can be explained by the result of fertilization of an unreduced egg with haploid sperm [16, 17]. In comparison with diploid sorts, by triploid sorts have been identified positive qualities: weakly expressed periodicity of fruiting, increased self-fruitfulness, large fruits of good

\footnotetext{
*Corresponding author: sirius0775@mail.ru
} 
quality with a long storage period and an increased content of vitamins. In addition, there is observed an expansion of the norm of reaction to environmental conditions $[3,15,18,19$, 20].

In the 70 s the selection significant by apple tree sorts were subjected to a karyological assessment, and in many of them polyploid series have been identified Malus silvestris $(2 \mathrm{n}=34,51)$, Malus coronaria $(2 \mathrm{n}=34,68)$, Malus hupehensis $(2 \mathrm{n}=34,51,68)$, Malus sargentii $(2 \mathrm{n}=34,51,68)$, Malus sieboldii $(2 \mathrm{n}=34,51,68)$, Malus $\times$ prunifolia $(2 \mathrm{n}=34,51$, 68) $[6,7,8]$. It is established that by the species

Malus toringo, Malus glaucescens, Malus rockii, Malus transitoria, Malus lancifolia, Malus glabrata, Malus platicarpa side be side with diploid forms, there are triploid and tetraploid forms, and only Malus baccata (the basis of the siberian assortment) does not have a polyploid row $[6,9,10]$.

Purposeful work on the creation of apple sorts at the polyploid level in Russia was started in 1970 at All-Russian Scientific Research Institute of Fruit Crop Breeding (c. Orel), later on the work joined employees of North caucasus federal scientific center of horticulture, viticulture \& winemaking (c. Krasnodar) [3, 18, 20, 21], where were obtained the sorts: Avgusta, Aleksandr Bojko, Bezhin Lug, Blagodat', Vavilovskoe, Darena, Zhilinskoe, Maslovskoe, Ministr Kisilev, Orlovskij partizan, Osipovskoe, Patriot, Prazdnichnoe, Spasskoe, Turgenevskoe, Yablochnyj spas, Rodnichok, Soyuz.

Part of them are included in the State Register of Breeding Achievements [20]. From diploid initial forms are distinguished spontaneous triploid sorts: Nizkorosloe, Pamyat' Semakinu, Rozhdestvenskoe, Sinap Orlovskij, Yubilyar.

The best effectiveness of practical breeding for the purpose of creating triploid sorts was obtained from heteroploidy crosses $2 \mathrm{x} \times 4 \mathrm{x}, 4 \mathrm{x} \times 2 \mathrm{x}[3,21,23]$.

Types of apple trees (initial forms) that participated in the creation of initial forms and Altai sorts (M. baccata, M.×prunifolia, M. sylvestris, M. sieversii, M. orientalis и $M$. Praecox) like the Altai sorts, they have a diploid set of chromosomes $(2 \mathrm{x}=34)$.

In Barnaul breeders isolated single spontaneous hybrids with a triple set of chromosomes [22].

At all stages of breeding is necessary cytological control of the hybrid fund, which is very labour-intensive [23, 24].

Selection and analysis of the material at the polyploid level must be carried out on a large experimental material [3].

Considering, that the polyploid state leads to changes in the cytological, anatomical, morphological and physiological characteristics of plants, it is assumed, that morphological signs can be used as markers in the select of highlyploid plants from a hybrid population [25].

The purpose of our research: to identify a complex of morphological markers associated with increased ploidy (triploidy) for the select of valuable genotypes of apple-trees from heterploid crosses by the juvenile stage of development.

\section{Objects and methods of research}

The studies were carried out in the period 2009-2014. The hybrid material was evaluated in a mini breeding nursery in a volume of 2419 hybrids from heteroploidy crosses, including 1191 hybrids crossed in 2009, 2010 - 639, $2012-1105$.

In the first year of growth was evaluated the potential of the hybrid material's resistance to scab on an artificial infectious ground in the open ground- "A method for select scabresistant apple sorts and seedlings on artificial infectious grounds" [27].

In the second year of growth, the receipting hybrid seedlings were evaluated by the strength of growth, degree of culture (assessment of selection), leaf thickness (micrometer 
by 3 measurements of 3 typical leaves in the middle part of the current growth), leaf index (typical leaves were collected in a herbarium for calculating the ratio of leaf length and width), description of the petiole and stipules (in laboratory conditions) [30].

The ploidy of hybrid seedlings was determined by counting the number of chromosomes on time-pressed preparations stained with acetic hematoxylin by the method of L. A. Topil'skaya, S. V. Luchnikova, N. P. CHuvashina by using a microscope Micmed 6-7 [31].

In the processing of the data and identifying the correlation was used statistical programs "Biogen".

\section{Results and discussion}

The selection mini breeding nursery of apple hybrids was placed on the slope of the northeastern exposure, which is limited by a blowing forest belt with an admixture of siberian apple-trees susceptible and medium-resistant to scab on the eastern and southern sides, that creates favorable conditions for the presence of primary infection on the lot of the mini breeding nursery at the time of artificial infection.

Abundant dews provided natural moistening of the leaf surface by the crops from $20 \mathrm{pm}$ to $12-14 \mathrm{pm}$ the next day.

The best period for artificial scab infecting by the open ground in the Altai low mountains is from July 20 to August 1 with optimal conditions for infecting: active growth of seedlings, the presence of drip moisture, humidity of air $80-86 \%$ and an average air temperature of $18 \ldots 20^{\circ} \mathrm{C}[28,29]$.

The lack of moisture was leveled by watering. The suspension was applied once by a manual sprayer before 1-2 hours of the dew fell.

Infected seedlings were kept for 2 days in conditions of a wet chamber under the shelter of a plastic film, they were shaded on sunny days.

The registration of the degree by damage was taken into account after 28-30 days by 6 classes of damage.

For assess the potential of the hybrid material resistance to scab on an artificial infectious background in the open ground in the first year of growth was used fresh inoculum of scab populations, which are widespread in the Altai low mountains from leaves and fruits of sorts by various genetic and geographical origin: Tayozhnoe, Ranetka purpurovaya, Kitajka zolotaya rannyaya, Syurpriz, Ven'yaminovskoe, Pepinka altajskaya, Studencheskoe, Altajskoe yubilejnoe, Rannee aloe and susceptible hybrids.

Two-year-old hybrids were evaluated by a complex of characteristics. Cytological screening of hybrid forms, selected by morphobiological characteristics was performed on the apical meristem, for this on the autumn was harvested an annual growth, which were stored in a snow burt before the start of regrowth.

Buds' fixation was carried out in winter from growing cuttings in the laboratory conditions of the studied specimens.

The growing of cuttings was carried out in room conditions by a temperature of $20^{\circ}$ after the end of the deep dormancy period on the end of the third decade of December. Regrowth is at the same time and, depending from the initial forms, occurs on 4-6 day, with the sum of positive temperatures of $70-110^{\circ} \mathrm{C}$. The beginning of buds fixation was carried out in the green cone phase in acetic alcohol for 5-6 pcs. from one sample. The storage of the buds before counting the chromosomes in alcohol (70\%) took place in the refrigerator. Chromosome counting was carried out according to the method [31].

It is accepted for the zero theory the maximum manifestation of morphological signs of two-year-old plants (leaf thickness, leaf index, leaf petiole length, stipule length and width, 
selection level of cultivated plant, growth strength and stem diameter, scab resistance) in the selection mini breeding nursery.

Amongst the hybrids of the first generation (F1) of $M$. baccata is traced the dominance of the species in transmitting its "wild" traits to offspring. Thus, in combinations of using $30-47-88$ as a pollinator, the culture of seedlings did not exceed 2.0 points (Table 1 ). In subsequent generations (F3 and F4), the average level culture of seedlings obtained with the participation of the tetraploid 30-47-88, 25-37-45 increased to 3.3-4.2 points. The number of seedlings estimated at 4.0-5.0 mark in these combinations ranged from 39 to $56 \%$.

The variation coefficient of the trait is high - from 15 to $33 \%$.

Depending on the initial forms, the average height of two-year-old hybrids by pollination 30-47-88 varied from $34(M$. baccata $4 \times 30-47-88)$ to $60 \mathrm{~cm}(16-83-2415 \times 30$ 47-88), 25-37-45 - from 42 (16-83-2415 × 25-37-45) to $63 \mathrm{~cm}$ (Gornoaltayskoe $\times 25-37-$ $45)$. The range of variation of the sign is strong and in all combinations is high - from 24 to $58 \%$. On average growth strength hybrid seedlings obtained in 5 heterploid combinations $(2 x \times 4 x)$ were significantly inferior to hybrids obtained in diploid crosses $(2 x \times 2 x)$ of the same parent initial forms.

The thickness of the leaf by pollinating forms was: by the tetraploid $30-47-88-0.34$ microns, $25-37-45(4 \mathrm{x})-0.33$ microns. In combinations of crossing with the tetraploid form $30-47-88$, the thickness of leaf of seedlings varies from $0.10-0.14$ to $0.27-0.34$ microns. The level of variability of the sign is at an average level ( $\mathrm{V}=14-21 \%)$.

The analysis of dispersion for 4 combinations of $M$. baccata $\times 30-47-88$ revealed no significant differences in this sign with the tetraploid initial form by 14 seedlings, or in 3.5 $\%$ of genotypes.

In hybrid populations with cultivars $25-37-45$, the minimum thickness of the leaf was 0.16-0.24 microns, the maximum $0.27-0.36$ microns, depending on the combination. The coefficient of variation - medium and high.

The index of the leaf according to the researchers' reports tends to 1.0 with an increase of ploidy by varietal sorts of apple (the width of the leaf is increasing).

This statement is taken by us, as a null theory. The average index of leaf in families from crosses of $2 \mathrm{x} \times 4 \mathrm{x}$ varied from 1.27 (Ranetka purpurovaya $\times 25-37-45$ ) to 1.91 (Malus baccata $\times 30-47-88$ ).

Hybrids with an index of leaf less than and equal to 1.0 were founding in 19 combinations from 40. The maximum value of the leaf index was 3.0 (Malus baccata $\times 30$ 47-88). The coefficient of variation in all combinations of crossing is an average level and higher from $10-26 \%$.

Seedlings were selected by groups in hybrid families based on the results of measurements of the morphometric parameters of hybrids, with an orientation to the maximum manifestation of signs and an analysis of dispersion for the smallest significant difference $\left(\mathrm{LSD}_{05}\right)$ in thickness of leaf compared to the thickness of a leaf with a tetraploid initial shape:

1. Hybrids with a thickness of leaf is not inferior and superior to the polyploid initial form and a leaf index close to 1.0.

2. Hybrids with a leaf thickness that is not inferior and superior to the polyploid initial form with a leaf index of more than 1.15.

3. Hybrids with a leaf thickness are inferior to the polyploid initial form and a leaf index up to 1.15 , the level of culture is $4-5$ marks. 
Table 1. Morphological signs of apple hybrids from heterploid crosses

\begin{tabular}{|c|c|c|c|c|c|c|c|c|c|c|}
\hline \multirow[t]{2}{*}{ Combination } & \multirow{2}{*}{ 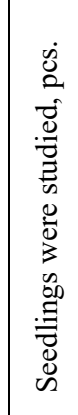 } & \multicolumn{3}{|c|}{ 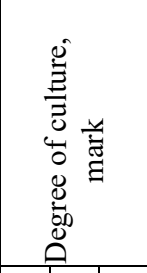 } & \multicolumn{3}{|c|}{ 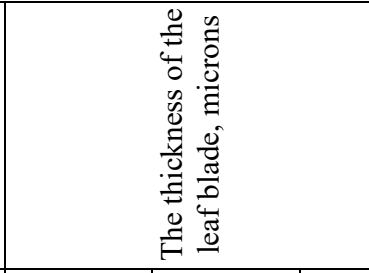 } & \multicolumn{3}{|c|}{ 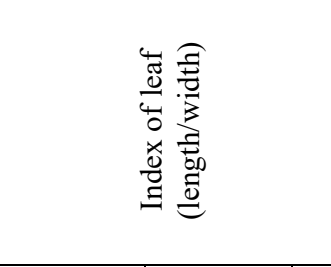 } \\
\hline & & 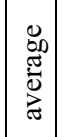 & $\mid \begin{array}{c}\underset{\Xi}{\Xi} \\
\stackrel{\Xi}{\Xi} \\
. \Xi\end{array}$ & $\begin{array}{l}\partial^{0} \\
>^{\prime}\end{array}$ & $\begin{array}{l}\Xi \\
\pm \\
\sum\end{array}$ & 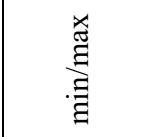 & $\partial^{\circ}$ & $\begin{array}{l}\Xi \\
\text { H } \\
\Sigma\end{array}$ & 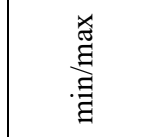 & $\begin{array}{l}\partial^{\circ} \\
>\end{array}$ \\
\hline \multicolumn{11}{|c|}{ Crossing of 2009 year } \\
\hline M. baccata $1 \times 30-47-88(4 \mathrm{x})$ & 29 & 2 & - & - & $0.21 \pm 0.07$ & $0.13 / 0.31$ & 19 & $1.91 \pm 0.04$ & $1.29 / 2.43$ & 12 \\
\hline M. baccata $2 \times 30-47-88(4 \mathrm{x})$ & 68 & 2 & - & - & $0.21 \pm 0.03$ & $0.13 / 0.27$ & 14 & $1.91 \pm 0.04$ & $1.09 / 2.79$ & 18 \\
\hline M. baccata $3 \times 30-47-88(4 \mathrm{x})$ & 35 & 2 & - & - & $0.22 \pm 0.05$ & $0.14 / 0.28$ & 14 & $1.78 \pm 0.04$ & $1.27 / 2.36$ & 13 \\
\hline M. baccata $4 \times 30-47-88(4 \mathrm{x})$ & 263 & 2 & $2 / 3$ & 6 & $0.22 \pm 0.02$ & $0.12 / 0.31$ & 16 & $1.87 \pm 0.02$ & $1.14 / 3.00$ & 16 \\
\hline $\begin{array}{l}\text { Altajskoe purpurovoe } \times 30-47-8 \\
(4 \mathrm{x})\end{array}$ & 103 & 3.3 & $2 / 5$ & 25 & $0.24 \pm 0.03$ & $0.12 / 0.32$ & 15 & $1.33 \pm 0.02$ & $0.92 / 1.88$ & 15 \\
\hline $\begin{array}{l}\text { Podarok sadovodam } \times 30-47-8 \\
(4 \mathrm{x})\end{array}$ & 130 & 3.3 & $2 / 5$ & 27 & $0.24 \pm 0.03$ & $0.12 / 0.29$ & 17 & $1.48 \pm 0.02$ & $0.97 / 2.38$ & 15 \\
\hline Suvenir Altaya $\times 30-47-88(4 \mathrm{x})$ & 123 & 3.3 & $2 / 5$ & 30 & $0.22 \pm 0.03$ & $0.14 / 0.34$ & 17 & $1.35 \pm 0.02$ & $0.98 / 1.93$ & 14 \\
\hline Co-81-907 × 30-47-88 (4x) & 161 & 3.4 & $2 / 5$ & 29 & $26 \pm 0.03$ & $0.13 / 0.33$ & 14 & $1.42 \pm 0.02$ & $1.00 / 2.28$ & 16 \\
\hline $16-83-2415 \times 30-47-88(4 x)$ & 110 & 3.5 & $1 / 5$ & 33 & $0.21 \pm 0.04$ & $0.10 / 0.31$ & 21 & & $0.91 / 2.24$ & 19 \\
\hline Total & 1022 & & & & & & & & & \\
\hline \multicolumn{11}{|c|}{ Crossing of 2010 year } \\
\hline M.b. $4 \times 25-37-45$ & 2 & - & 0 & - & & \begin{tabular}{|l|l|}
$0.17 / 0.29$ \\
\end{tabular} & 27 & & $1.30 / 2.17$ & 26 \\
\hline $\begin{array}{l}\text { Altajskoe purpurovoe } \times 25-37-45 \\
(4 \mathrm{x})\end{array}$ & 129 & 3.5 & $2 / 5$ & 26 & $0.24 \pm 0.03$ & $0.16 / 0.31$ & 12 & $1.28 \pm 0.33$ & $1.00 / 1.78$ & 26 \\
\hline Gornoaltajskoe $\times 25-37-45(4 \mathrm{x})$ & 31 & 3.3 & $2 / 5$ & 27 & $0.25 \pm 0.06$ & $0.21 / 0.33$ & 25 & $1.34 \pm 0.32$ & $1.12 / 1.66$ & 24 \\
\hline Suvenir Altaya $\times 25-37-45$ & 5 & 4.2 & $3 / 5$ & 15 & 0.2 & $0.22 / 0.30$ & 13 & $1.58 \pm 0.09$ & $0.98 / 1.93$ & 6 \\
\hline $\begin{array}{l}\text { Pepinka altajskaya } \times 25-37-45 \\
(4 \mathrm{x})\end{array}$ & 44 & 3.0 & $2 / 4$ & 17 & $0.23 \pm 0.03$ & $0.17 / 0.30$ & 12 & $1.42 \pm 0.15$ & $1.17 / 1.67$ & 10 \\
\hline Tolunaj $\times 25-37-45(4 \mathrm{x})$ & 45 & 3.9 & $2 / 5$ & 26 & $0.26 \pm 0.03$ & $0.18 / 0.33$ & 13 & $1.30 \pm 0.2$ & $1,00 / 2.22$ & 18 \\
\hline Co-81 & 193 & 3.3 & $2 / 5$ & 25 & $0.23 \pm 0.05$ & $0.16 / 0.33$ & 23 & $1.41 \pm 0.36$ & $1.05 / 2.06$ & 26 \\
\hline $16-83-2415 \times 25-37-45(4 \mathrm{x})$ & 46 & 2.9 & $2 / 5$ & 29 & $0.25 \pm 0.03$ & $0.19 / 0.31$ & 12 & $1.45 \pm 0.03$ & $0.91 / 2.24$ & 19 \\
\hline $9-87-4936 \times 25-37-45(4 x)$ & 101 & 3.3 & $2 / 5$ & 23 & $0.23 \pm 0.03$ & $0.18 / 0.31$ & 12 & $1.43 \pm 0.3$ & $0.88 / 2.08$ & 18 \\
\hline Total & 596 & & & & & & & & & \\
\hline \multicolumn{11}{|c|}{ Crossing of 2012 year } \\
\hline $\begin{array}{l}\text { Nezhnoe zabajkal'skoe } \times 25-37-4 \\
(4 \mathrm{x})\end{array}$ & 160 & 3.7 & $2 / 5$ & 23 & $0.28 \pm 0.03$ & $0.18 / 0.36$ & 12 & $1.32 \pm 0.03$ & $0.95 / 2.00$ & 14 \\
\hline $\begin{array}{l}\text { Ranetka purpurovaya } \times 25-37- \\
45(4 \mathrm{x})\end{array}$ & 204 & 3.7 & $2 / 5$ & 23 & $0.28 \pm 0.14$ & $0.18 / 0.34$ & 13 & $1.27 \pm 0.17$ & $0.97 / 1.95$ & 13 \\
\hline $\begin{array}{l}\text { Altajskij golubok } \times 25-37-45 \\
(4 \mathrm{x})\end{array}$ & 205 & 3.5 & $2 / 5$ & 26 & $0.27 \pm 0.03$ & $0.18 / 0.35$ & 12 & $1.37 \pm 0.22$ & $1.02 / 2.17$ & 16 \\
\hline Gornoaltajskoe $\times 25-37-45(4 \mathrm{x})$ & 79 & 3.6 & $2 / 5$ & 27 & $0.26 \pm 0.04$ & $0.16 / 0.33$ & 15 & $1.4 \pm 0.20$ & $0.98 / 2.46$ & 17 \\
\hline $\begin{array}{l}\text { Pepinka altajskaya } \times 25-37-45 \\
(4 \mathrm{x})\end{array}$ & 19 & 3.7 & $3 / 5$ & 19 & $0.26 \pm 0.05$ & $0.16 / 0.32$ & 19 & $1.32 \pm 0.23$ & $0.94 / 1.63$ & 17 \\
\hline $\begin{array}{l}\text { Ranetka celinnaya } \times 25-37-45 \\
(4 \mathrm{x})\end{array}$ & 27 & 3.4 & $2 / 5$ & 29 & $0.25 \pm 0.04$ & $0.17 / 0.33$ & 17 & $1.40 \pm 0.30$ & $1.09 / 2.29$ & 19 \\
\hline Suvenir Altaya $\times 25-37-45(4 \mathrm{x})$ & 85 & 3.8 & $2 / 5$ & 22 & $0.27 \pm 0.03$ & $0.19 / 0.35$ & 13 & $1.36 \pm 0.24$ & $0.97 / 2.29$ & 18 \\
\hline Co-61-632 × 25-37-45 (4x) & 22 & 3.3 & $2 / 5$ & 22 & $0.23 \pm 0.03$ & $0.18 / 0.30$ & 14 & $1.45 \pm 0.23$ & $1.15 / 1.88$ & 16 \\
\hline Total & 801 & & & & & & & & & \\
\hline n all & 2419 & & & & & & & & & \\
\hline
\end{tabular}




\section{Evaluation of hybrids crossing a 2009}

From the hybrid population of the donor of diploid gametes 30-47-88 were isolated 66 samples by a complex of 10 signs for the subsequent assessment of their ploidy on the second year.

The number of triploid seedlings (from the total studied number) depends on the combination of crossing. In crosses of $2 x \times 4 x$ their quota varies from $20 \%$ (Podarok sadovodam $\times 30-47-88)$ to $88 \%(16-83-2415 \times 30-47-88)$. Triploids were identified in 5 combinations. At the same time in the families from crosses Altajskoe purpurovoe $\times 30-47$ 88 and Co-81-907 $\times 30-47-88$ were identified four tetraploid forms $(2 \mathrm{n}=68)$.

On the basis of morphobiological signs of hybrid seedlings in a selections nursery in order to establish their conjugation with a triploid set of chromosomes in the combinations of crossing from the maternal initial forms Altajskoe purpurovoe, Suvenir Altaya, Co-81907 was revealed the degree of correlation.

For large excerption were calculated the correlation to coefficients r-Kendall, for small ones with the number of objects equal to the number of features - r-Spearman, because they analyze the relationships between variables more fully and in detail, sorting all possible correspondences between pairs of values and accurately take account the quantitative degree of connection between variables.

In the combinations of crossing Altajskoe purpurovoe $\times 30-47-88$ was established an inverse correlation between ploidy and leaf thickness $(-0.941$, at R05 $=0.487$; R01 $=$ $0.640)$, as well as a direct relationship between the index and thickness of leaf ( 0.547 and 0.777). It was revealed a significant correlation between the degree of culture and the triploid set of chromosomes $(0.875)$, which has a direct orientation.

In the combinations of crossing Co-81-907 $\times 30-47-88$ and Suvenir Altaya $\times 30-47-88$ was established a negative (inverse) correlation between the triploid set of seedling chromosomes and the leaf index. It can be assumed, that this dependence is common to all hybrids, independently of the combination of crossing. By hybrids of the family Co-81-907 $\times 30-47-88$ was found a direct correlation between the index and the thickness of leaf $(0.291$ at R05 $=0.244)$, and as well as an inverse conjugation between the triploid set of chromosomes and the index of leaf $(-0.953$ at R01 $=0.320)$.

Thus, they are identified 3 types of conjugations:

- I order: conjugacy of signs with a triploid set of seedling chromosomes from intervalent crosses (ploidy/sign);

- II order: the conjugacy between signs closely related to the triploid set of chromosomes and other morphological signs;

- III order: significant correlations between signs that are not associated with a triploid set of chromosomes.

With aim to confirm the obtained results to the combinations of crosses, they were combined according to the paternal component into a common array, that made it possible to include families with small samples in the analysis.

The analysis of correlations between culture and other characteristics in various heterploid groups indicates the presence of a negative relationship between the culture of the seedling and the leaf index, as well as between the index and ploidy.

The analysis of correlations between cultivated and other characteristics in various heterploid groups indicates at the presence of a negative relationship between the cultivated of the seedling and the index of leaf, as well as between the index and ploidy. But the conjugacy between cultivated and a triploid set of chromosomes in any variant exists and has both positive and negative values. The revealed correlations of the stem diameter with other morphological characteristics were not significant for us (Table 2). No correlation between the height of apple trees and their ploidy has been established. Also, due to the nonuniqueness of the established links with culture and ploidy was required additional 
research. In subsequent studies by the conjugacy of the indicators " force of growth" and "stem diameter" of two-year-old hybrid seedlings with ploidy were excluded from accounting and analysis.

\section{Evaluation of hybrids crossing in 2010}

According to the results of the dispersion analysis of morphological signs by hybrids of the 2010 crossing, they were selected 78 (14\%) hybrid seedlings to assess ploidy. Correlations of signs were evaluated in combinations of crossing with sorts Gornoaltayskoye, Altayskoye purpurovoye, Tolunai, 16-83-2415 (Suvenir Altaya × Ermakovskoye gornoye), Co-81-907 (Co × Altayskoye yubileynoye), 9-87-4936 (Ermakovskoye gornoye $\times$ Orlik).

In the combination of 16-83-2415 $\times 25-37-45(4 x)$, the analyzed selection (5 seedlings) is sufficient for statistical analysis, but not sufficient for objective analysis.

In all combinations of crossing with 25-37-45 (4x) was revealed a relationship of the I order of ploidy/thickness of leaf with an accuracy level of $1 \%$.

In combinations with the sorts Gornoaltayskoye and Altayskoye purpurovoye was established a negative relationship of the I order by signs of ploidy/leaf index. In combinations with the above-mentioned sorts and the form Co-81-907 there is both a negative, and a positive relationship of the I order between the signs of ploidy/level of culture, which indicates the instability of this complex.

In the combinations of the donor of diploid with sorts Altayskoye purpurovoye, Tolunai and 9-87-4936 was found an inverse relationship between the signs of ploidy/ the degree of damage of scab, which is proved at the $1 \%$ level. The negative association with scab is confirmed by a negative association with the index of leaf (the association of index of leaf/ damage of scab is positive).

Table 2. Conjugacy of signs by a hybrid population sort $\times 30-47-88(4 \mathrm{x})$

\begin{tabular}{|c|c|c|c|c|c|c|c|c|}
\hline Sign & $\frac{\frac{2}{0}}{\frac{0}{2}}$ & 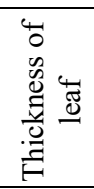 & 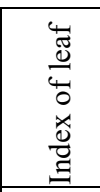 & 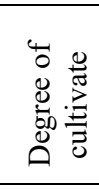 & 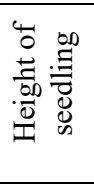 & 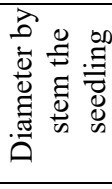 & 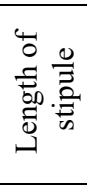 & 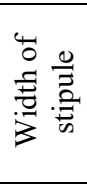 \\
\hline Ploidy & 1 & 0.151 & -0.035 & 0.224 & 0.146 & - & - & - \\
\hline Thickness of leaf & 0.151 & 1 & 0.430 & - & - & 0.246 & - & - \\
\hline Index of leaf & -0.035 & 0.430 & 1 & - & - & 0.196 & - & - \\
\hline Degree of cultivate & 0.224 & - & - & 1 & 0.410 & 0.348 & 0.204 & - \\
\hline Height of seedling & 0.146 & - & - & 0.410 & 1 & 0.538 & 0.219 & - \\
\hline $\begin{array}{l}\text { Diameter by stem the } \\
\text { seedling }\end{array}$ & - & 0.246 & 0.196 & 0.348 & 0.538 & 1 & 0.225 & - \\
\hline Length of stipule & - & - & - & 0.204 & 0.219 & 0.225 & 1 & 0.700 \\
\hline Width of stipule & - & - & - & - & - & - & 0.700 & 1 \\
\hline
\end{tabular}

at the level of $1 \%$ : $\mathrm{R}=0.2170$; at the level of $5 \%: \mathrm{R}=0.1651^{*}+$ positive value coefficient of the correlation; - negative value coefficient of the correlation.

In all combinations of crossing was revealed an inverse relationship of the degree of cultivate/index of leaf, which may also be an indirect relationship with the ploidy of hybrids (Table 3), was established an inverse relationship between the degree damage of scab / the degree of cultivate, provable at the $1 \%$ level.

In the studied combinations, there was no relationship between the ploidy/length of the 
petiole of leaf.

The correlation of the signs - length and width of the stipule for all families is not pronounced in significant signs (ploidy, thickness of leaf, index of leaf, cultivate), but it is close to each other.

Table 3. Conjugacy of signs in a hybrid population sort $\times 25-37-45$ (4x), crosses in 2010

\begin{tabular}{|c|c|c|c|c|c|c|c|c|}
\hline Sign & $\frac{\overrightarrow{0}}{\frac{0}{2}}$ & 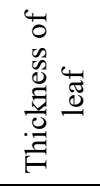 & 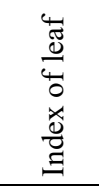 & 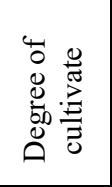 & 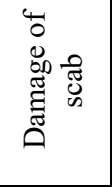 & 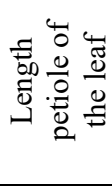 & 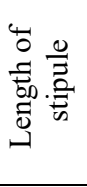 & 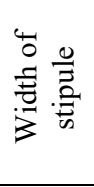 \\
\hline Ploidy & 1.00 & -0.369 & 0.599 & -0.286 & - & - & - & - \\
\hline Thickness of leaf & -0.369 & 1.00 & -0.288 & - & -0.625 & - & - & -0.217 \\
\hline Index of leaf & 0.599 & -0.288 & 1.00 & - & - & - & - & - \\
\hline Degree of cultivate & -0.286 & - & - & 1.00 & -0.468 & 0.221 & - & - \\
\hline Damage of scab & - & -0.625 & - & -0.468 & 1.00 & - & - & - \\
\hline Length petiole of the leaf & - & - & - & 0.221 & - & 1.00 & 0.361 & - \\
\hline Length of stipule & - & - & - & - & - & 0.361 & 1.00 & 0.764 \\
\hline Width of stipule & - & -0.217 & - & - & - & - & 0.764 & 1.00 \\
\hline
\end{tabular}

at the level of $1 \%: \mathrm{R}=0.190$; at the level of $5 \%: \mathrm{R}=0.145$

Among the isolated seedlings, 41 (53\%) have a triploid and tetraploid set of chromosomes $(3 \mathrm{x}, 4 \mathrm{x})$. Five tetraploid seedlings $(6 \%$ from the number studied for karyotype) were isolated in combinations of crossing sorts Altayskoye purpurovoye, Pepinka altajskaya, Tolunai, 16-83-2415 with a tetraploid form 25-37-45 (4x).

The part of triploid seedlings relative to the studied ones is $46 \%$ (36 pcs.), and depending on the combination of crossing, it ranges from 0 to $55 \%$.

\section{Evaluation of hybrids crossing in 2012}

Among the hybrids of the 2012 crossing were selected 272 hybrid seedlings ( $30 \%$ of the studied seedlings) for assessment for karyotype by morphological signs. In all combinations of crossing with 25-37-45 (4x) was established a relationship of the I order of ploidy/thickness of leaf (Table 4). From the 7 combinations analyzed with the sorts Nezhnoe zabajkal'skoe, Co-61-632 were revealed a relationship of the I order ploidy/index of leaf and a relationship of the II order thickness of leaf/index of leaf in combinations with the varieties Ranetka purpurovaya, Suvenir Altaya.

The degree of of cultivate and damage of scab have a relationship of II order with the index of leaf and the degree of cultivate. Relationships of the III order were revealed in all combinations by crossing between the length and width of the stipule, the length of the leaf petiole in combination with the sort Nezhnoe zabajkal'skoe, the ploidy/length and width of the stipule have a relationship of the I order; as the lack of permanent connections with the ploidy of these signs, their regisrtation $\mathrm{i}$ can be to neglect $\mathrm{n}$ further work. The results obtained in a sample from 222 objects of sort $\times 25-37-45(4 \mathrm{x})$ confirm the previous conclusions on combinations of crossing and indicate the presence of relationships of the I order ploidy/ thickness of leaf and thickness of leaf/index of leaf, degree of cultivate and the II order - degree of cultivate/degree by damage of scab. 
Table 4. Conjugacy of signs in a hybrid population sort $\times 25-37-45$ (4x) crosses in 2012

\begin{tabular}{|c|c|c|c|c|c|c|c|c|}
\hline Sign & $\frac{\frac{3}{0}}{\frac{0}{2}}$ & 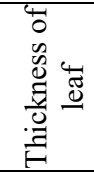 & 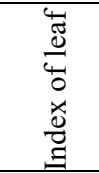 & 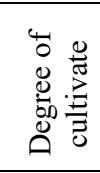 & 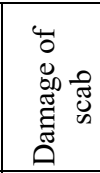 & 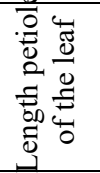 & 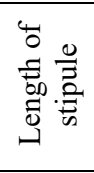 & 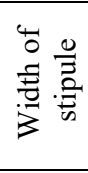 \\
\hline Ploidy & 1 & 0.420 & & & & & & \\
\hline Thickness of leaf & 0.420 & 1 & 0.107 & 0.102 & & & & \\
\hline Index of leaf & & 0.107 & 1 & -0.116 & & & & \\
\hline Degree of cultivate & & 0.102 & -0.116 & 1 & -0.294 & 0.140 & 0.129 & 0.094 \\
\hline Damage of scab & & & & -0.294 & 1 & & & \\
\hline $\begin{array}{l}\text { Length petiole of the } \\
\text { leaf }\end{array}$ & & & & 0.140 & & 1 & 0.150 & 0.101 \\
\hline Length of stipule & & & & 0.129 & & 0.150 & 1 & 0.739 \\
\hline Width of stipule & & & & 0.094 & & 0.101 & 0.739 & 1 \\
\hline
\end{tabular}

at the level of $1 \%: \mathrm{R}=0.1162$ at the level of $5 \% \mathrm{R}=0.0884$

Among the isolated seedlings $215(79 \%)$ are triploids (3x). According to the results of cytological screening, seedlings with a triple set of chromosomes were isolated in all combinations, except Co-61-632 × 25-37-45.

The proportion of triploids relative to the studied hybrids in the combination of the donor of diploid gametes 25-37-45 (4x) with the sort Nezhnoe zabajkal'skoe is $90 \%$, Ranetka purpurovaya - 94\%, Altajskij golubok - 82\%, Gornoaltajskoe - 81\%, Pepinka altajskaya - 100\%, Ranetka celinnaya - 100\%, Suvenir Altaya - 85\%, Yunga - 25\%.

\section{Conclusions}

During the assessment of hybrid heterploid populations obtained from genetically dissimilar donors of diploid gametes were revealed correlations of the triple set of chromosomes and thickness of leaf, index of leaf and degree of cultivate.

A significant correlation was revealed with a sign associated with a triploid set of chromosomes: the degree of cultivate/degree damage of scab and index of leaf, thickness of leaflindex of leaf, degree damage of scab and length of stipule, index of leafl length petiole of leaf. The use of morphological markers significantly reduces the volume of cytological assessment of karyotypes by hybrids selected on a complex of morphological signs.

According from the results of the assessment depending on the initial forms in the breeding nursery of apple hybrids from heteroploidy crosses, according to morphological signs were identified from 14 to $100 \%$ of seedlings with a triploid set of chromosomes.

In the selection of apple-trees at the polyploid level by identifying seedlings with a triploid set of chromosomes at the early stages within a hybrid population from heteroploidy crosses we recommend a complex of morphological markers of a triploid set of chromosomes: thickness of leaf, index of leaf, degree of cultivate.

\section{References}

1. P. M. Zhukovsky, Polyploidy and breeding, Proceedings of the meeting, January 1418. 1963 (M.-L., Nauka, 1965) 
2. A. A. Zhuchenko, Ecological genetics of cultivated plants (as an independent scientific discipline) (Krasnodar, 2010)

3. E. N. Sedov, G. A. Sedysheva, Z. M. Serova, The role of polyploidy in apple tree breeding (Orel, 2008)

4. V. A. Rybin, Proceedings on Applied Botany Genetics and breeding, 17(3) (1927)

5. B. Nebel, Zur Cytologie von Malus und Vitis. Gartenbauwissenschaft, BD 1 (1929)

6. L.V. Soloveva, Cytology and genetics, 13, 15 (1979)

7. V. V. Ponomarenko, K. V. Ponomarenko, Gene pool of the species of the genus Malus Mill. Apple tree. Biology. Morphology. Taxonomy. The source material (St. Petersburg, 2013)

8. M. Schuster, R. Battner, Genetic Resources and Crop Evolution, 42 (1995)

9. H. D. Rundlel, P. Nosil, Ecol. Let. 8, 3 (2005)

10. L. Guo-Li, L. Xiao-Li, Phytotacsonomica Sinica Acta. 31(3) (1993).

11. O. N. Barsukov, Works on applied botany, genetics and breeding, 161 (2007)

12. E. V. Ulyanovsk, T. G. Prichko, L. D. Chalaya, Vavilov Journal of Genetics and Breeding, 20(5) (2016)

13. E. N. Sedov, G. Sedysheva, Z. M. Serova, Bulletin of the Russian Academy of agricultural Sciences, 3 (2011)

14. G. A. Sedysheva, N. G. Gorbacheva, Journal of Plant Science 1(2) (2013)

15. J. Janick, J. N. Cummins, S. K. Brown, M. Hemmat, Breed Fruit, Apple, Vol. I. (Jules Janick and James N. Moore, New York, 1996)

16. V. N. Lisnev, Genetics, 12, 8 (1976)

17. A. V. Pikunova, E. N. Sedov, S. V. Tokmakov, I. I. Suprun, N. G. Gorbachev, M. A. Dolzhikova, T. V. Yanchuk, Z. M. Serova, Genetics, 54, 4 (2018)

18. E. N. Sedov, Journal of Plant Science, 1(3) (2013)

19. E. Sedov, G. Sedysheva, Z. Serova, E. Ulyanovskaya, Russian Journal of Horticulture, 1 (1) (2014)

20. E. N. Sedov, G. Sedysheva, Z. M. Serova, E. V. Ulyanovsk, Horticulture and viticulture, 6 (2011)

21. Innovation in changing the genome of Apple. New perspectives in breeding. Monograph (Orel, 2015)

22. A. S. Sankina, T. F. Kornienko, Siberian Bulletin of Agricultural Science, 2 (1980)

23. G. A. Sedysheva, E. N. Sedov, N. G. Gorbachev, Z. M. Serova, S. A. Miller, Contemporary horticulture, 1 (2017)

24. G. A. Sedysheva, E. N. Sedov, N. G. Gorbacheva, Z. M. Serova, S. A. Melnik, Achievements of science and technology of the agro-industrial complex, 7 (2013)

25. G. V. Eremin, Modern methodological aspects of the organization of the breeding process in horticulture and viticulture (Krasnodar, 2012)

26. V. E. Perfiliev, Methodological issues of research on genetics and selection of fruit crops, Genetics and research of the most important signs of fruit plants. Sat. dokl. i soob. XIV Michurinskiy readings 27-28 October 1993, Michurinsk (1994)

27. Method for selection of scab-resistant varieties and seedlings of apple trees on an artificial infectious background (Moscow, VASKHNIL, 1985)

28. S. A. Makarenko, S. N. Artyukh, Fruit growing and viticulture of South Russia, 35(5) 
(2015)

29. S. A. Makarenko, S. N. Artyukh, Fruit growing, 27 (2015)

30. Program and methodology of selection of fruit, berry and nut crops (Orel, VNIISPK 1995)

31. Cytological studies of fruit and berry crops (Michurinsk, TSGL, 1976) 